\title{
Application of Potassium Ferrate in Water Treatment Processes
}

\author{
Olena Ivanenko', Tetyana Shabliy', Yuliia Nosachova ${ }^{1 *}$ \\ 1 Department of Ecology and Technology of Plant Polymers, Faculty of Chemical Engineering, Igor Sikorsky \\ Kyiv Polytechnic Institute, Peremogy Avenu 37/4, 03056 Kyiv, Ukraine \\ * Corresponding author's e-mail: j.nosachova@gmail.com
}

\begin{abstract}
The paper presents the results of the investigation on the efficiency of the potassium ferrate application in water conditioning processes: oxidation of pollutants of different composition by ferrate compounds; clarification of model solutions by coagulation; reduction of corrosive aggressiveness of aqueous solutions. The optimal conditions for the water clarification process using potassium ferrate were: reagent dose $1 \mathrm{mg} \cdot \mathrm{dm}^{-3}, \mathrm{pH}$ close to neutral, and temperature $20^{\circ} \mathrm{C}$. The oxidation rate of organic substances by the potassium ferrate solutions was $50 \%$ when applied in concentrations of $15-20 \mathrm{mg} \cdot \mathrm{dm}^{-3}$. The studies on the possible application of the reagent as a steel corrosion inhibitor in neutral aqueous media were conducted. The degree of corrosion protection reached $60 \%$, which indicated the prospect of using iron (VI) compounds as inhibitory additives.
\end{abstract}

Keywords: ferrate technology, water conditioning, coagulation, oxidation, corrosion inhibitor, potassium ferrate.

\section{INTRODUCTION}

With the widespread introduction of the resource saving technologies in the water conditioning processes, it is extremely important and necessary to search for new reagents that would combine not only their high quality and safety, but also their multiple uses both as coagulant and as disinfectant. The most available reagent - aluminum sulfate - is often used at water treatment stations as a coagulant, but more valuable aluminum hydroxosulfate is added in small doses in winter to improve the separation process of coarse particles. The most common method of water disinfection and oxidation of hardly oxidizable organic compounds is chlorination. However, its use results in the formation of even more toxic products than the original pollutants. The absence of aftereffect significantly limits the application of ozone as an effective destructive reagent at water treatment plants and in sewage systems.

The use of alkali metal ferrates (VI) [Sharma et al. 2004], due to their multifunctional effect, is a new and quite promising method of water purification. Ferrates (VI) are one of the strongest oxidizing agents that can decompose many toxic substances into low-toxic products and cause the death of microorganisms. The product of the ferrates decomposition in a solution is iron hydroxide, i.e. a low-toxic product $\mathrm{Fe}(\mathrm{OH})_{3}$ is released in the form of colloidal aggregates with a highly developed surface that effectively adsorb heavy metal ions, suspension particles and organic residues, providing additional water purification by coagulation of pollutants [Perfilyev et al. 2004].

Therefore, the purpose of this work was to determine the possibility of potassium ferrate application in the processes of water treatment and water conditioning as a coagulant, oxidant and corrosion inhibitor.

\section{EXPERIMENTAL}

\section{Materials and methods}

A model solution was used to evaluate the efficiency of water clarification. Red clay was used as an opacifier, which was added to distilled water to create turbidity $100 \mathrm{mg} \cdot \mathrm{dm}^{-3}$. Potassium ferrate 
(VI), aluminum sulfate (III) and iron sulfate (III) were used as coagulants.

The sample volume was $250 \mathrm{~cm}^{3}$. The change in parameters was determined with the photocolorimetric method using a photocolorimeter KFK-2. The initial turbidity value was recorded; its change in each sample was measured every 20 minutes for 2 hours. The residual iron concentration was measured after the coagulation process.

Potassium ferrate was used at various concentrations in order to evaluate the efficiency of water purification by the oxidation of organic pollutants. Separate solutions of phenol and dyes (methylene blue and direct black) with an initial concentration $50 \mathrm{mg} \cdot \mathrm{dm}^{-3}$ were used as model solutions. The reagents were added to a model solution, and the final pollutant concentration was measured after one hour of mixing.

The degree of efficiency of purification/ clarification $(Z)$ was calculated by means of the formula:

$$
z=\frac{C_{\text {init }}-C_{\text {fin }}}{C_{\text {init }}} \cdot 100 \%
$$

where: $C_{\text {init }}$ is the initial concentration of suspended particulate matter/contaminant, $\mathrm{mg} \cdot \mathrm{dm}^{-3}, C_{\text {fin }}$ is the final concentration of suspended particulate matter/contaminant at the end of experiment, $\mathrm{mg} \cdot \mathrm{dm}^{-3}$.

\section{Investigation of potassium ferrate inhibitory properties}

The efficiency of potassium ferrate as a steel corrosion inhibitor was determined with the massometric method. The samples of the steel 20 plates were sanded with sandpaper until complete removal of rust and other surface contaminants (the quality was controlled to obtain a bright "silver" surface over the entire sample area). After removal of residual of organic contaminants, the dry samples were weighed on the analytical scale. The plates were then immersed in water with different concentrations of potassium ferrate. Additionally, a series of experiments were performed with the addition of sodium tripolyphosphate and sodium hexametaphosphate. The exposure time was 62 hours. Afterwards, the corrosion products were removed from the samples; the samples were dried and weighed again.

The following indicators were calculated after conducting the experiments:

- massometric corrosion index:

$$
\mathrm{K}_{\mathrm{m}}=\frac{m_{1}-m_{2}}{s \cdot \tau}, \mathrm{g} \cdot \mathrm{m}^{-2} \cdot \mathrm{h}^{-1}
$$

where: $m_{1}$ is the mass of the steel plate at the beginning of the experiment, $g, m_{2}$ is the mass of steel plate after removal of corrosion products, $\mathrm{g}, S$ is the surface area of the plate, $\mathrm{m}^{2}, \tau$-time, hour.

- deep corrosion index:

$$
\mathrm{K}_{\mathrm{n}}=8.76 \cdot \frac{K_{m}}{\rho}, \mathrm{mm} \cdot \text { year }^{-1}
$$

where: $K_{m}$ is the massometric corrosion index, $\mathrm{g} \cdot \mathrm{m}^{-}$

${ }^{2} \cdot \mathrm{h}^{-1}, \rho$ is the metal density, $\mathrm{g} \cdot \mathrm{cm}^{-3}, 8.76$ is the factor, calculated by dividing the number of hours per year (8760) by 1000 .

- inhibitory factor $\left(K_{b}\right)$ :

$$
\mathrm{K}_{\mathrm{b}}=\frac{\mathrm{K}_{m}^{0}}{K_{m i}}
$$

where: $K_{m}{ }^{0}$ is the massometric corrosion index without and inhibitor, $\mathrm{g} \cdot \mathrm{m}^{-2} \cdot \mathrm{h}^{-1}, K_{m i}$ is the massometric corrosion index with an inhibitor, $\mathrm{g} \cdot \mathrm{m}^{-2} \cdot \mathrm{h}^{-1}$.

- degree of corrosion protection:

$$
\mathrm{Z}=\left(1-\frac{1}{\mathrm{~K}_{\mathrm{b}}}\right) \cdot 100, \%
$$

Residual concentrations of aluminum, iron, phenol and dyes were determined using standard photocolorimetric methods [Lurie and Rybnikova 1974, Kulskij et al. 1980].

\section{DISCUSSION AND RESULTS}

At the first stage of the study, the effectiveness of the turbidity reduction of the red clay model solution was investigated using potassium ferrate at different initial conditions.

The first step in the study was to determine the impact of potassium ferrate dose on the turbidity reduction of the initial solution with a concentration of red clay $100 \mathrm{mg} \cdot \mathrm{dm}^{-3}$ (Fig. 1).

Since potassium ferrate has a very high redox potential $(2.02 \mathrm{~V}$ in acidic medium and $0.72 \mathrm{~V}$ in neutral medium), it is possible to use it as a coagulant in fairly small concentrations of 1 to 20 $\mathrm{mg} \cdot \mathrm{dm}^{-3}$ of $\mathrm{Fe}$ ions. The oxidation of suspended solids with a ferrate method can also alter the properties of their surface, making these particles easily removed by coagulation. Iron hydroxide is a by-product of the water treatment with potassium ferrate that also exhibits strong coagulating properties [Jia-Qian Jiang et al. 2013].

As it can be seen from Figure 1, when treating water with potassium ferrate at different 
concentrations, the most effective dose of coagulant was $1 \mathrm{mg} \cdot \mathrm{dm}^{-3}$. Thus, this experiment confirmed the effectiveness of ferrate in water

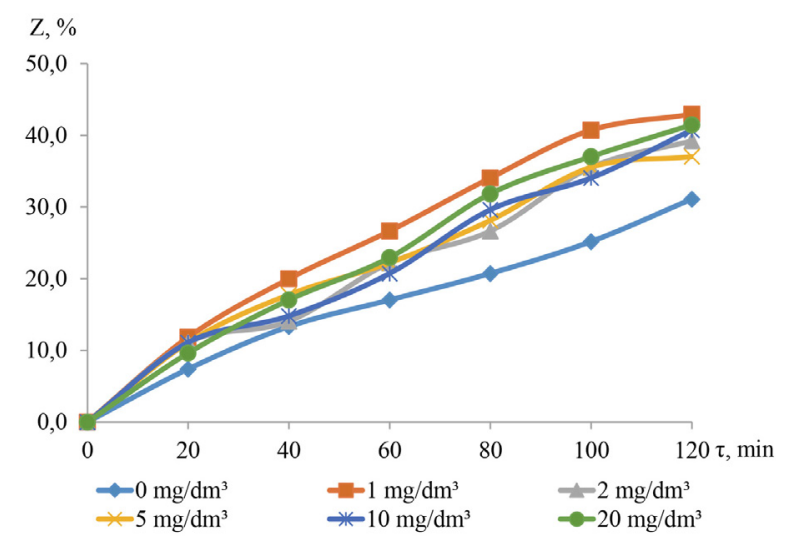

Figure 1. The impact of dose of potassium ferrate on the efficiency of turbidity reduction of the model red clay solution $\left(C_{\text {init }}=100 \mathrm{mg} \cdot \mathrm{dm}^{-3}\right)$

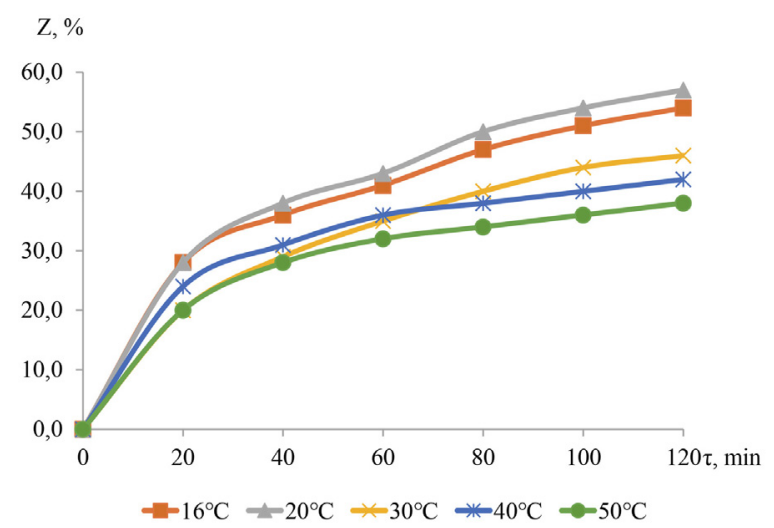

Figure 2. Turbidity reduction of the red clay model solution $\left(C_{\text {init }}=100 \mathrm{mg} \cdot \mathrm{dm}^{-3}\right)$ with potassium ferrate at different temperatures

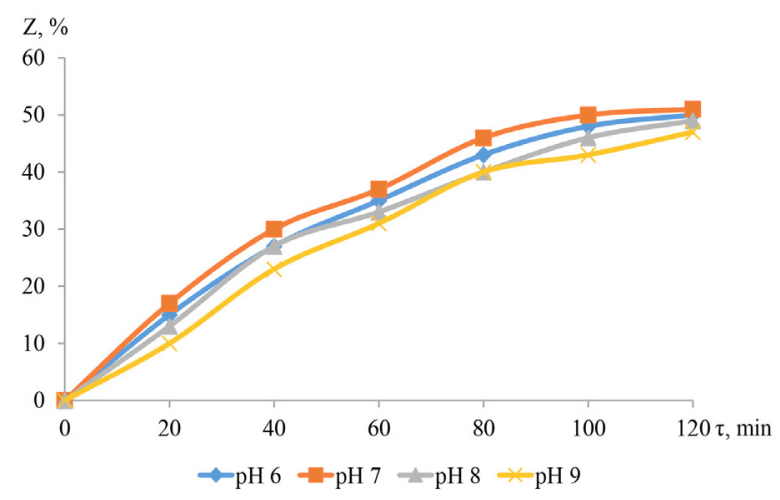

Figure 3. Turbidity reduction of the red clay model solution $\left(C_{\text {init }}=100 \mathrm{mg} \cdot \mathrm{dm}^{-3}\right)$ at different $\mathrm{pH}$ in the presence of potassium ferrate clarification processes at low concentrations. At higher concentrations of coagulant, the decrease in purification efficiency was observed,

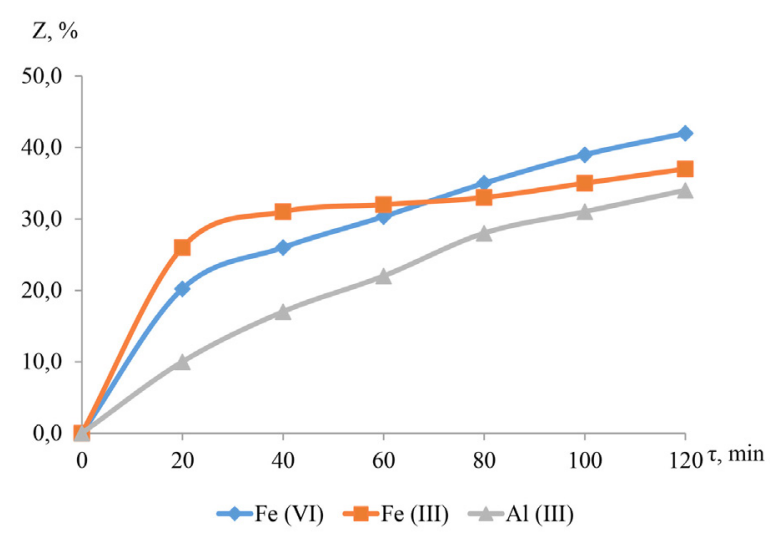

Figure 4. Turbidity reduction of the red clay model solution $\left(C_{\text {init }}=100 \mathrm{mg} \cdot \mathrm{dm}^{-3}\right)$ using potassium ferrate, aluminum sulfate and iron (III) sulfate at a concentration of $1 \mathrm{mg} \cdot \mathrm{dm}^{-3}$

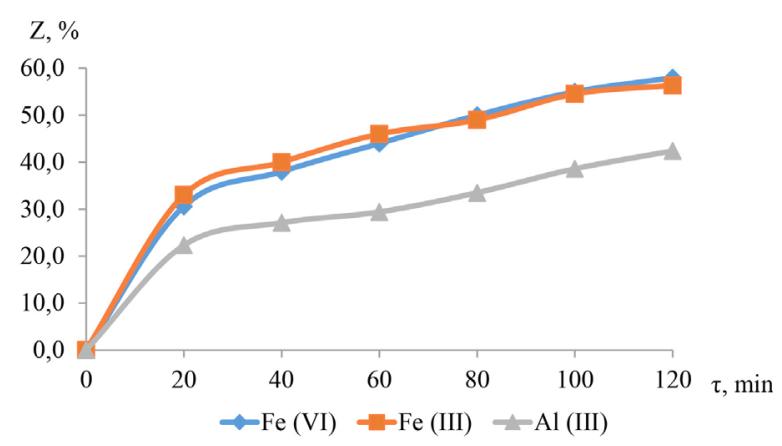

Figure 5. Turbidity reduction of the red clay model solution $\left(C_{\text {init }}=100 \mathrm{mg} \cdot \mathrm{dm}^{-3}\right)$ using potassium ferrate, aluminum sulfate and iron sulfate at a concentration of $1 \mathrm{mg} \cdot \mathrm{dm}^{-3}$ and temperature of $20^{\circ} \mathrm{C}$

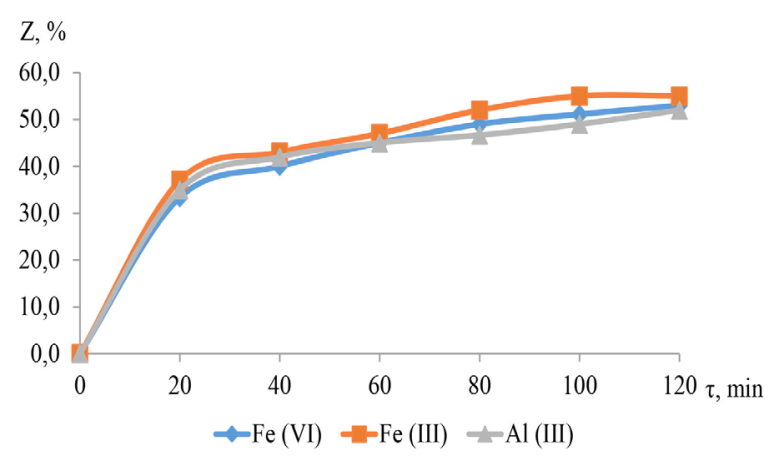

Figure 6. Turbidity reduction of rthe ed clay model solution $\left(C_{\text {init }}=100 \mathrm{mg} \cdot \mathrm{dm}^{-3}\right)$ using potassium ferrate, aluminum sulfate and iron sulfate at a dose of $1 \mathrm{mg} \cdot \mathrm{dm}^{-3}$, temperature of $20^{\circ} \mathrm{C}$ and $\mathrm{pH} 7$ 


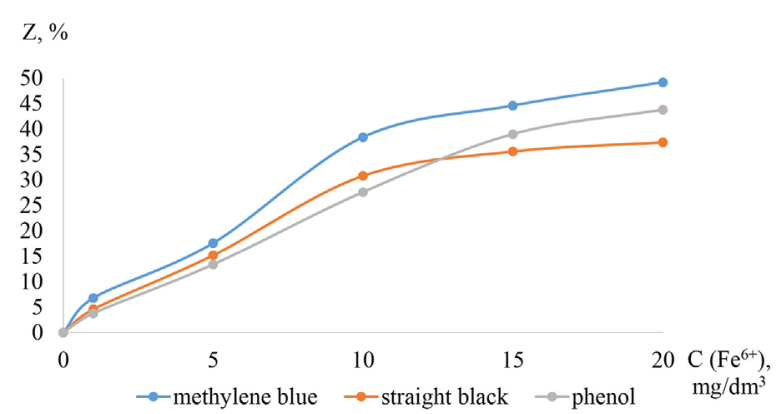

Figure 7. The impact of dose of potassium ferrate on the efficiency of reduction of the organic matter content $\left(C_{\text {init }}=50 \mathrm{mg} \cdot \mathrm{dm}^{-3}\right)$

which may be caused by an additional contamination of iron ions due to the reduction of iron (VI) to iron (III).

Different temperature regimes were used to optimize the process of water clarification using potassium ferrate. The results of using combined water treatment to increase the efficiency of turbidity reduction are shown in Figure 2.

It can be concluded from Figure 2 that the optimal temperature for water turbidity reduction in the presence of potassium ferrate $\left(1 \mathrm{mg} \cdot \mathrm{dm}^{-3}\right)$ is $20^{\circ} \mathrm{C}$. Decreased treatment efficiency at higher temperature may be related to the premature oxidation of ferrate. Under these conditions, the clarification efficiency of water was about $60 \%$.

The effect of $\mathrm{pH}$ on the potassium ferrate efficiency in the water clarification processes was also studied. The results of the effectiveness of turbidity reduction in the red clay solution are shown in Figure 3.

The study showed that $\mathrm{pH}$ did not significantly affect the clarification process of turbid water. The best result was obtained at $\mathrm{pH} 7$. The degree of water clarification was $50 \%$. The use of ferrate in a slightly alkaline or slightly acidic solution gave the results close to those obtained in neutral environment that allows the use of this coagulant in the slightly acidic-alkaline $\mathrm{pH}$ range 6-8.

For the comparison of potassium ferrate efficiency with other known coagulants, the experiments were conducted with their use at the same dose $1 \mathrm{mg} \cdot \mathrm{dm}^{-3}$ of the Fe ions that was determined from the previous studies to be quite effective. Typically, the most common coagulants - aluminum sulfate and iron (III) sulfate - are used in the water conditioning and water treatment processes at much larger doses (20-40 $\mathrm{mg} \cdot \mathrm{dm}^{-3}$ of metal). However, the goal was to compare the effectiveness of coagulants at their low concentrations, since increasing the concentrations of the reagent leads to an increase in the cost of the process.

The results of the effectiveness of turbidity reduction of the red clay solution are shown in Figure 4 . The potassium ferrate was the most effective $(Z=42 \%)$ after 2 hours of coagulation, compared to iron sulfate and aluminum sulfate. Iron sulfate at a concentration $1 \mathrm{mg} \cdot \mathrm{dm}^{-3}$ at showed the highest efficiency the beginning of the process, reaching the peak value of $30 \%$, though its efficiency remained unchanged over time. Aluminum sulfate in this case exhibited the lowest efficiency, although the coagulation capacity was observed throughout the coagulation process. Potassium ferrate provided uniform water clarification throughout the coagulation process.

The comparison of the efficiency of potassium ferrate, aluminum sulfate and iron sulfate in turbidity reduction of the model solution at $20^{\circ} \mathrm{C}$, i.e. at a temperature optimal for water treatment with potassium ferrate is shown in Figure 5. The least effective coagulant at a given temperature was aluminum sulfate. Potassium ferrate and iron sulfate had almost the same efficiency under these conditions. The degree of water clarification reached $50 \%$.

The effectiveness of turbidity reduction of the red clay solution using potassium ferrate, aluminum sulfate and iron sulfate under optimal conditions $-\mathrm{pH} \mathrm{7}$, concentration of $1 \mathrm{mg} \cdot \mathrm{dm}^{-3}$ (of metal), and temperature of $20^{\circ} \mathrm{C}$ - was investigated. The results are shown in Figure 6. The diagrams indicate that at a given $\mathrm{pH}$ value the used coagulants were equally effective.

It is known from the publications, that besides the coagulating properties, potassium ferrate also effectively oxidizes organic contaminants, decomposing them to simple substances [Sharma 2010, 2011; Graham et al. 2004]. Since organic contaminants are always present in natural water, potassium ferrate may have advantages over other coagulants because of its ability to provide integrated water treatment. Therefore, the task of the second stage of the research was to assess the efficiency of the use of potassium ferrate in the oxidation processes of the organic contaminants in water. The model solutions of phenol, methylene blue and direct black at a concentration of $50 \mathrm{mg} \cdot \mathrm{dm}^{-3}$ were used.

The reduction of organic contaminants concentration was achieved by the addition of potassium ferrate at concentrations of $1-20 \mathrm{mg} \cdot \mathrm{dm}^{-3}$ with contact time equal to 1 hour. 
Figure 7 shows that there was a minimum oxidation efficiency at concentration $1 \mathrm{mg} \cdot \mathrm{dm}^{-3}$ for all three substances. At this concentration, the coagulating properties of potassium ferrate were most effective. In the case of methylene blue, there was a dramatic increase in efficiency as the concentration of potassium ferrate increased to $10 \mathrm{mg} \cdot \mathrm{dm}^{-3}$ $(\mathrm{Z}=38 \%)$ and a further steady increase of efficiency to almost $50 \%$ at increasing the reagent concentration. The oxidation efficiency of direct black steadily increased to a concentration of potassium ferrate $10 \mathrm{mg} \cdot \mathrm{dm}^{-3}$, further on the purification index was almost constant. In the case of phenol, there was a uniform increase in the oxidation efficiency as the concentration of potassium ferrate increased. However, it was generally possible to achieve $40-50 \%$ efficiency at a potassium ferrate dose of $15-20 \mathrm{mg} \cdot \mathrm{dm}^{-3}$ of $\mathrm{Fe}^{6+}$.

Table 1. Efficiency of steel 20 protection against corrosion using a potassium ferrate solution

\begin{tabular}{|c|c|c|c|}
\hline $\begin{array}{l}\text { Dose of potassium ferrate }\left(\mathrm{Fe}^{6+}\right) \\
\mathrm{mg} \cdot \mathrm{dm}^{-3}\end{array}$ & $\mathrm{~K}_{\mathrm{n}}, \mathrm{mm} \cdot$ year $^{-1}$ & $\mathrm{~K}_{\mathrm{b}}$ & $Z, \%$ \\
\hline \multicolumn{4}{|c|}{ Model solution based on distilled water } \\
\hline 0 & 0.1033 & - & - \\
\hline 1 & 0.0970 & 1.06 & 6.10 \\
\hline 2 & 0.0910 & 1.14 & 11.91 \\
\hline 5 & 0.0802 & 1.29 & 22.36 \\
\hline 10 & 0.0770 & 1.34 & 25.46 \\
\hline 15 & 0.0730 & 1.42 & 29.33 \\
\hline 20 & 0.0669 & 1.54 & 35.24 \\
\hline \multicolumn{4}{|c|}{ Model solution based on tap water } \\
\hline 0 & 0.1098 & - & - \\
\hline 1 & 0.1030 & 1.07 & 6.19 \\
\hline 2 & 0.0990 & 1.11 & 9.84 \\
\hline 5 & 0.0866 & 1.27 & 21.16 \\
\hline 10 & 0.0836 & 1.31 & 23.90 \\
\hline 15 & 0.0772 & 1.42 & 29.66 \\
\hline 20 & 0.0736 & 1.49 & 32.99 \\
\hline
\end{tabular}

Table 2. Efficiency of steel 20 protection against corrosion in an aqueous medium using sodium tripolyphosphate and potassium ferrate

\begin{tabular}{|c|c|c|c|c|}
\hline $\begin{array}{c}\text { Dose of }\left(\mathrm{Na}_{5} \mathrm{P}_{3} \mathrm{O}_{10}\right), \\
\mathrm{mg} \cdot \mathrm{dm}^{-3}\end{array}$ & $\begin{array}{c}\text { Dose of potassium ferrate }\left(\mathrm{Fe}^{6+}\right), \\
\mathrm{mg} \cdot \mathrm{dm}^{-3}\end{array}$ & $\mathrm{~K}_{\mathrm{n}}, \mathrm{mm} \cdot \mathrm{year}{ }^{-1}$ & $\mathrm{~K}_{\mathrm{b}}$ & $\mathrm{Z}, \%$ \\
\hline \multicolumn{5}{|c|}{ Model solution based on distilled water } \\
\hline 5 & 0 & 0.0650 & 1.59 & 37.08 \\
\hline 5 & 1 & 0.0647 & 1.60 & 37.37 \\
\hline 5 & 2 & 0.0630 & 1.64 & 39.01 \\
\hline 5 & 5 & 0.0601 & 1.72 & 41.82 \\
\hline 5 & 10 & 0.0580 & 1.78 & 43.85 \\
\hline 5 & 15 & 0.0561 & 1.84 & 45.69 \\
\hline 5 & 20 & 0.0550 & 1.88 & 46.76 \\
\hline & Model solution based on tap water & \multicolumn{3}{|c|}{} \\
\hline 5 & 0 & 0.0827 & 1.33 & 24.73 \\
\hline 5 & 1 & 0.0794 & 1.38 & 27.69 \\
\hline 5 & 2 & 0.0770 & 1.43 & 29.91 \\
\hline 5 & 5 & 0.0699 & 1.57 & 36.38 \\
\hline 5 & 10 & 0.0664 & 1.65 & 39.56 \\
\hline 5 & 15 & 0.0648 & 1.69 & 41.00 \\
\hline 5 & 20 & 0.0600 & 1.83 & 45.36 \\
\hline
\end{tabular}


Table 3. Efficiency of steel 20 protection against corrosion in an aqueous medium using the solutions of sodium hexametaphosphate and potassium ferrate

\begin{tabular}{|c|c|c|c|c|}
\hline $\begin{array}{c}\text { Dose of }\left(\mathrm{Na}_{6} \mathrm{O}_{18} \mathrm{P}_{6}\right), \\
\mathrm{mg} \cdot \mathrm{dm}^{-3}\end{array}$ & $\begin{array}{c}\text { Dose of potassium ferrate }\left(\mathrm{Fe}^{6+}\right), \\
\mathrm{mg} \cdot \mathrm{dm}^{-3}\end{array}$ & $\mathrm{~K}_{\mathrm{n}}, \mathrm{mm} \cdot \mathrm{year}{ }^{-1}$ & $\mathrm{~K}_{\mathrm{b}}$ & $\mathrm{Z}, \%$ \\
\hline \multicolumn{5}{|c|}{ Model solution based on distilled water } \\
\hline 5 & 0 & 0.063 & 1.65 & 39.50 \\
\hline 5 & 1 & 0.060 & 1.71 & 41.67 \\
\hline 5 & 2 & 0.058 & 1.80 & 44.30 \\
\hline 5 & 5 & 0.051 & 2.01 & 50.29 \\
\hline 5 & 10 & 0.048 & 2.17 & 54.02 \\
\hline 5 & 15 & 0.043 & 2.43 & 58.86 \\
\hline 5 & 20 & 0.038 & 2.72 & 63.21 \\
\hline & Model solution based on tap water & & 38.75 \\
\hline 5 & 0 & 0.067250 & 1.63 & 40.38 \\
\hline 5 & 1 & 0.065460 & 1.68 & 43.44 \\
\hline 5 & 2 & 0.062100 & 1.77 & 48.62 \\
\hline 5 & 5 & 0.056420 & 1.95 & 52.55 \\
\hline 5 & 10 & 0.052100 & 2.11 & 56.68 \\
\hline 5 & 15 & 0.047560 & 2.31 & 61.24 \\
\hline 5 & 20 & 0.042560 & 2.58 & \\
\hline
\end{tabular}

It is known that the inorganic substances with oxidizing properties (nitrites, molybdates, chromates, ferrates) can create protective oxide films on the metal surface, i.e. can act as metals corrosion inhibitors of passivation type. In this case, as a rule, there is a shift of the potential towards positive values corresponding to the release of oxygen from water molecules or hydroxyl ions. At the same time, oxygen atoms are formed on the metal; they block the most active centers of the metal surface and create an additional jump of potential that impedes the dissolution of the metal [Shabliy et al. 2017].

The properties of potassium ferrate as a corrosion inhibitor of steel in neutral and slightly acidic environments were investigated (Table 1).

The obtained data indicated that potassium ferrate was capable of providing corrosion protection degree up to $35 \%$. The deep corrosion index slightly increased in the case of model solutions with tap water (the protection degree was about $30 \%$ ). The inhibitory effect was almost absent at low concentrations, but in both cases the increase in the protection of the metal against corrosion was observed, starting with a concentration of ferrate higher than $5 \mathrm{mg} \cdot \mathrm{dm}^{-3}$.

The investigations were made with the simultaneous use of potassium ferrate with known phosphate inhibitors tripolyphosphate and sodium hexametaphosphate (Tables 2,3) to improve the effectiveness of steel protection against the corrosion processes.
The addition of sodium tripolyphosphate enhanced the anti-corrosion properties of potassium ferrate. The metal corrosion rate decreased from $0.1033-0.1098 \mathrm{~mm} \cdot$ year $^{-1}$ to $0.055-0.06 \mathrm{~mm} \cdot$ year $^{-1}$ for distilled and tap water, respectively. The protection degree increased to almost $50 \%$. The addition of a sodium hexametaphosphate reduced the corrosion rate for distilled and tap water from 0.1033-0.1098 $\mathrm{mm} \cdot$ year $^{-1}$ to $0.038-0.0426 \mathrm{~mm} \cdot$ year $^{-1}$, respectively. The protection degree of steel 20 exceeded $60 \%$.

\section{CONCLUSIONS}

Studies showed that the turbidity reduction of aqueous suspensions due to the use of potassium ferrate was an effective process, compared to the use of iron sulfate and aluminum sulfate. The optimal dose of the coagulant was $1 \mathrm{mg} \cdot \mathrm{dm}^{-3}$. It was found that the coagulation process was affected by the temperature conditions. The optimal temperature for water turbidity reduction with potassium ferrate was $20^{\circ} \mathrm{C}$. Decreased treatment efficiency at higher temperature may be related to the premature oxidation of ferrate. The change of $\mathrm{pH}$ did not significantly affect the water clarification process. The best result of water clarification was obtained at $\mathrm{pH} 7$, i.e. in a neutral medium.

The removal processes of organic pollutants from water were investigated on the example of dyes of different types and phenol. The treatment 
degree can reach 50\%. However, the oxidation efficiency did not exceed $10 \%$ for potassium ferrate at concentrations of $1 \mathrm{mg} \cdot \mathrm{dm}^{-3}$.

While evaluating the inhibitory properties of potassium ferrate, it was found that it can be used for corrosion rate reduction. In order to enhance the protective effect, it would be advisable to use it in combination with other inhibitors.

\section{REFERENCES}

1. Graham N., Jiang C.C., Li X.Z., Jiang J.Q., Ma J. The influence of $\mathrm{pH}$ on the degradation of phenol and chlorophenols by potassium ferrate. 2004. Chemosphere, 56(10), 949-956.

2. Jia-Qian Jiang, Hari Babu Prithiviraj Durai, Winzenbacher R., Petri M. 2013. Drinking water treatment by in-situ generated ferrate (VI). Proceedings of the 13th International Conference on Environmental Science and Technology. Athens, Greece.

3. Kulskij L.A., Goronowskij I.T., Koganowskij A.M., Szewczenko M.A. 1980. Справочник по свойствам, методам анализа и очистке воды. Naukowa dumka. Kijev.

4. Lurie J.J., Rybnikova A.I. 1974. Chimiczeskij analiz proizwodstwiennych stocznych wod. Chimja. Moskwa.

5. Perfilyev U.D., Kulykov L.A., Dedushenko S.K. 2004. Advanced ferrate water treatment technology. Moscow. Russia.

6. Shabliy T., Nosachova J., Radovenchik Y., Vember V. 2017. Study of effectiveness of heavy metals ions as the inhibitors of steel corrosion. Eastern-European Journal of Enterprise Technologies, 4/12(88), 10-16.

7. Sharma V.K. 2010. Oxidation of nitrogen-containing pollutants by novel ferrate (VI) technology. Journal of Environmental Science and Health, Part A - Toxic/Hazardous Substances \& Environmental Engineering, 45(6), 645-667.

8. Sharma V.K. Oxidation of inorganic contaminants by ferrates (VI, V, and IV)-kinetics and mechanisms. 2011. Journal of Environmental Management, 92(4), 1051-1073.

9. Sharma V.K., Jiang J.Q., Bouzek K. 2004. Innovative ferrate (VI) technology in water and wastewater treatment. Thesis. Proceedings of Internat. Symp. Prague, Czech Republic. 